\title{
Experimental investigation of hypersonic boundary-layer transition on a cone model in the High Enthalpy Shock Tunnel (HEG) at Mach 7.5
}

\author{
Alexander Wagner*, Stuart Laurence ${ }^{\dagger}$, Jan Martinez Schramm ${ }^{\ddagger}$, Klaus Hannemann ${ }^{\S}$ \\ German Aerospace Center (DLR), Institute of Aerodynamics and Flow Technology, Göttingen, Germany \\ Viola Wartemann , Heinrich Lüdekell \\ German Aerospace Center (DLR), Institute of Aerodynamics and Flow Technology, Braunschweig, Germany \\ Hideyuki Tanno*, Katsuhiro Ito $^{\dagger \dagger}$ \\ Japan Aerospace Exploration Agency (JAXA), Kakuda Space Center, Kakuda Miyagi 981-1525 JAPAN
}

\begin{abstract}
Hypersonic boundary-layer transition on a $7^{\circ}$ half-angle cone was investigated experimentally in the DLR High Enthalpy Shock Tunnel Göttingen (HEG) at Mach 7.5. The cone model, provided by the Japan Aerospace Exploration Agency (JAXA), has a length of $1100 \mathrm{~mm}$ and was tested with nose radii of $2.25 \mathrm{~mm}$ and $5 \mathrm{~mm}$. The free stream unit Reynolds number was varied over the range of $1.2 \times 10^{6} / \mathrm{m}$ to $6.2 \times 10^{6} / \mathrm{m}$ at a stagnation enthalpy of $H_{0}=3.3 \mathrm{MJ} / \mathrm{kg}$. The model was equipped with co-axial thermocouples to determine the transition location by means of the surface heat-flux distribution. Ten flush mountedpiezoelectric fast-response pressure transducers were used to measure the pressure fluctuations in the boundary-layer associated with second mode instabilities. The results are compared to stability calculations conducted with the DLR NOn-LOcal Transition analysis code, NOLOT.
\end{abstract}

\section{Nomenclature}

$\begin{array}{ll}a & \text { wave amplitude } \\ a_{0} & \text { wave amplitude at } x=x_{0} \\ L & \text { length of the cone model } \\ N & \text { N-factor } \\ q & \text { flow / material quantity } \\ R_{N} & \text { nose radius } \\ R e_{m} & \text { unit Reynolds number } \\ R e_{t} & \text { transition Reynolds number } \\ t & \text { Time } \\ u, v, w & \text { Velocity in x-, y-, z-coordinate } \\ x^{1}, x^{2}, x^{3} & \text { Coordinates in downstream, wall-normal and azimuthal direction }\end{array}$

\footnotetext{
*Research Scientist, Spacecraft Department, DLR Göttingen, Alexander.Wagner@dlr.de, Member AIAA

${ }^{\dagger}$ Research Scientist, Spacecraft Department, DLR Göttingen, Stuart.Laurence@dlr.de, Member AIAA

$\ddagger$ Research Scientist, Spacecraft Department, DLR Göttingen, Jan.Martinez@dlr.de, Member AIAA

$\S$ Head Spacecraft Department, DLR Göttingen, Klaus.Hannemann@dlr.de, Member AIAA

ๆResearch Scientist, Spacecraft Department, DLR Braunschweig, Viola.Wartemann@dlr.de

" Research Scientist, Spacecraft Department, DLR Braunschweig, Heinrich.Luedeke@dlr.de, Senior Member AIAA

**Associate Senior Researcher, JAXA, tanno.hideyuki@jaxa.jp, Member AIAA

††Senior Researcher, JAXA, Ito.Katsuhiro@jaxa.jp
} 


\section{Greek symbols \\ $\alpha, \beta \quad$ Wave numbers \\ $\sigma \quad$ Spatial growth rate \\ $\gamma \quad$ Ratio of specific heats \\ $\omega \quad$ Frequency}

\section{Indices}

$i \quad$ Imaginary part

$r \quad$ Real part

\section{Superscripts}

- Base flow quantity

Disturbance flow quantity

\section{Introduction}

A key factor in the aerothermodynamic design process of hypersonic flight vehicles is the correct prediction of heat-flux and skin friction, which are significantly influenced by laminar to turbulent boundary-layer transition. However, the mechanisms leading to transition are still poorly understood, resulting in uncertainty in the prediction of transition. ${ }^{1}$ Furthermore, ground-based boundary-layer transition studies are usually conducted in high-noise conventional wind tunnels or shock tunnels, with disturbance levels higher than in flight. Pate and Schueler ${ }^{2}$ conclusively demonstrated that the transition process is influenced by free-stream aerodynamic noise, which depends on the type of facility and the test conditions.

The scope of the present research activity is to address the facility dependence of the transition process in two similar impulse facilities, HIEST and HEG. Therefore, basic transition studies in HEG were conducted in order to compare with results obtained in the JAXA impulse facility HIEST. ${ }^{3}$ A $1100 \mathrm{~mm}$ long, $7^{\circ}$ halfangle cone model, corresponding to the HIFiRE I configuration, was exchanged between the two facilities to measure the transition location and the second mode instabilities at varying Reynolds numbers.

This paper covers the post-processing of the measurements conducted in HEG, including the results of stability calculations using the $\mathrm{NOLOT}^{4}$ code.

\section{High Enthalpy Shock Tunnel Göttingen (HEG)}

The HEG was commissioned for use in 1991. Since then it has been used extensively in a large number of national and international space and hypersonic flight projects.

Originally, the facility was designed for the investigation of the influence of high temperature effects such as chemical and thermal relaxation on the aerothermodynamics of entry or re-entry space vehicles. In this operating range, total specific enthalpies of up to $23 \mathrm{MJ} / \mathrm{kg}$ and nozzle stagnation pressures of up to $150 \mathrm{MPa}$ can be reached. In recent years its range of operating conditions has been subsequently extended, the main emphasis being to generate new test conditions which allow investigating the flow past hypersonic flight configurations from low altitude Mach 6 up to Mach 10 at approximately $33 \mathrm{~km}$ altitude. ${ }^{5,6}$

An overview of the HEG facility is given by the schematic and the pictures in figure 1. The overall length and mass of the facility are $60 \mathrm{~m}$ and $280 t$, respectively. The facility consists of a secondary reservoir, a compression tube, separated from an adjoining shock tube via the primary diaphragm, and a subsequent nozzle and test section. The HEG nominal operating condition XIII, XIV, XV and XVII were used for the present investigations. Condition XIII was designed to generate a free-stream flow which simulates approximately Mach 7.5 flight conditions at an altitude of about $28 \mathrm{~km}$. The averaged nozzle and the resulting free-stream conditions of the present HEG test campaign are provided in table 2. The total available test time is approximately 3 milliseconds, as shown in figure 3 . 

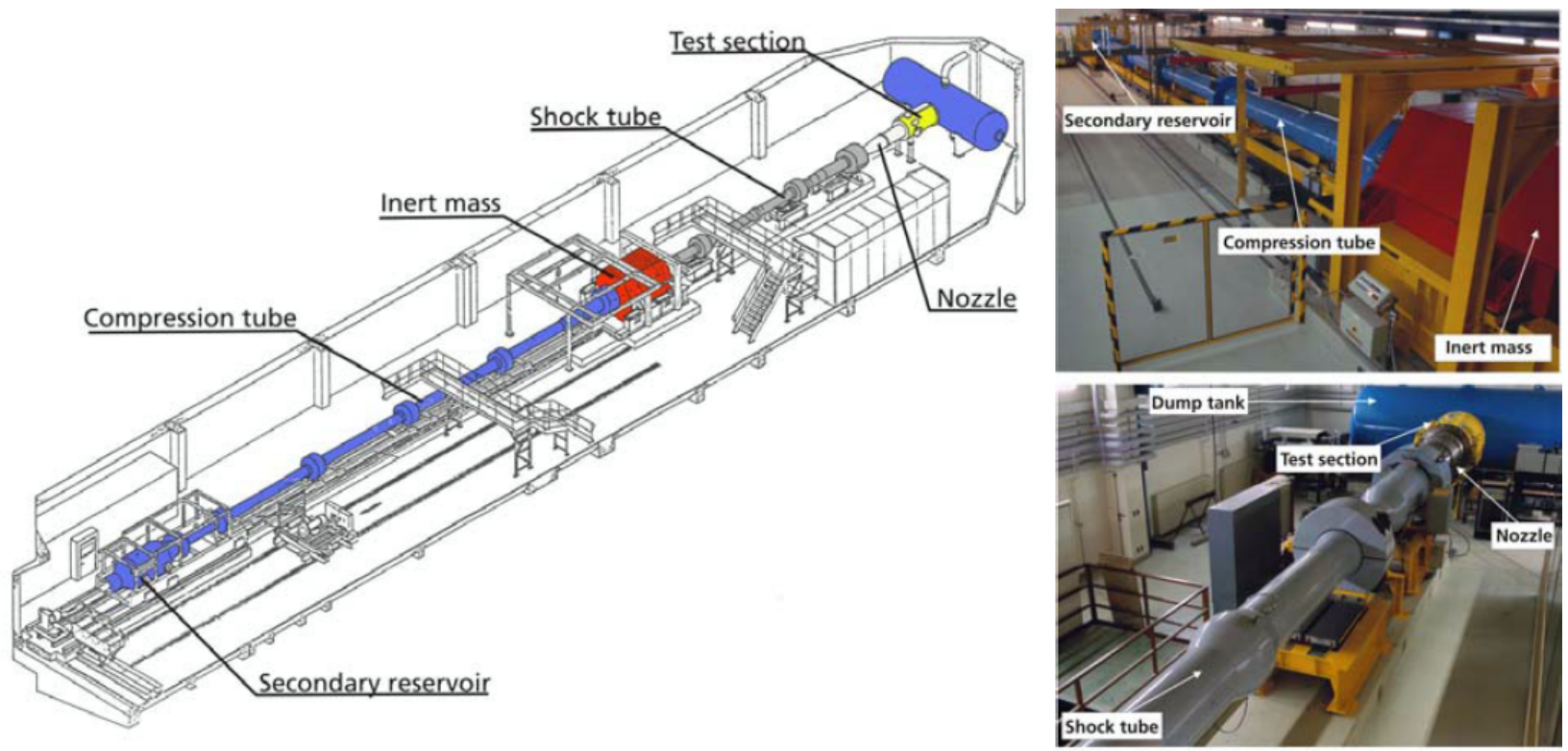

Figure 1. Schematic (left) and photographic views (right) of HEG

\section{Cone Model}

The cone model was a $7^{\circ}$ half-angle blunted cone with an overall length of $1100 \mathrm{~mm}$ and two exchangeable nose tips with nose radii of $2.25 \mathrm{~mm}$ and $5 \mathrm{~mm}^{7}$ The model was provided by JAXA and is, apart of the nose radius, identical to the forebody of the HIFiRE I flight experiment. ${ }^{8}$ Figure 2 shows the model before mounting in the HEG test section. The existing instrumentation was complemented with two additional fast response pressure transducers. Special attention was payed that no discontinuities were present on the model surface. The tested model was equipped with 121 thermocouples, 4 pressure transducers of type KULITE XCL-100-100A and 10 piezoelectric PCB132A37 fast response pressure transducers. The model was supported by a sting system in HEG at nominal $0^{\circ}$ angle of attack.

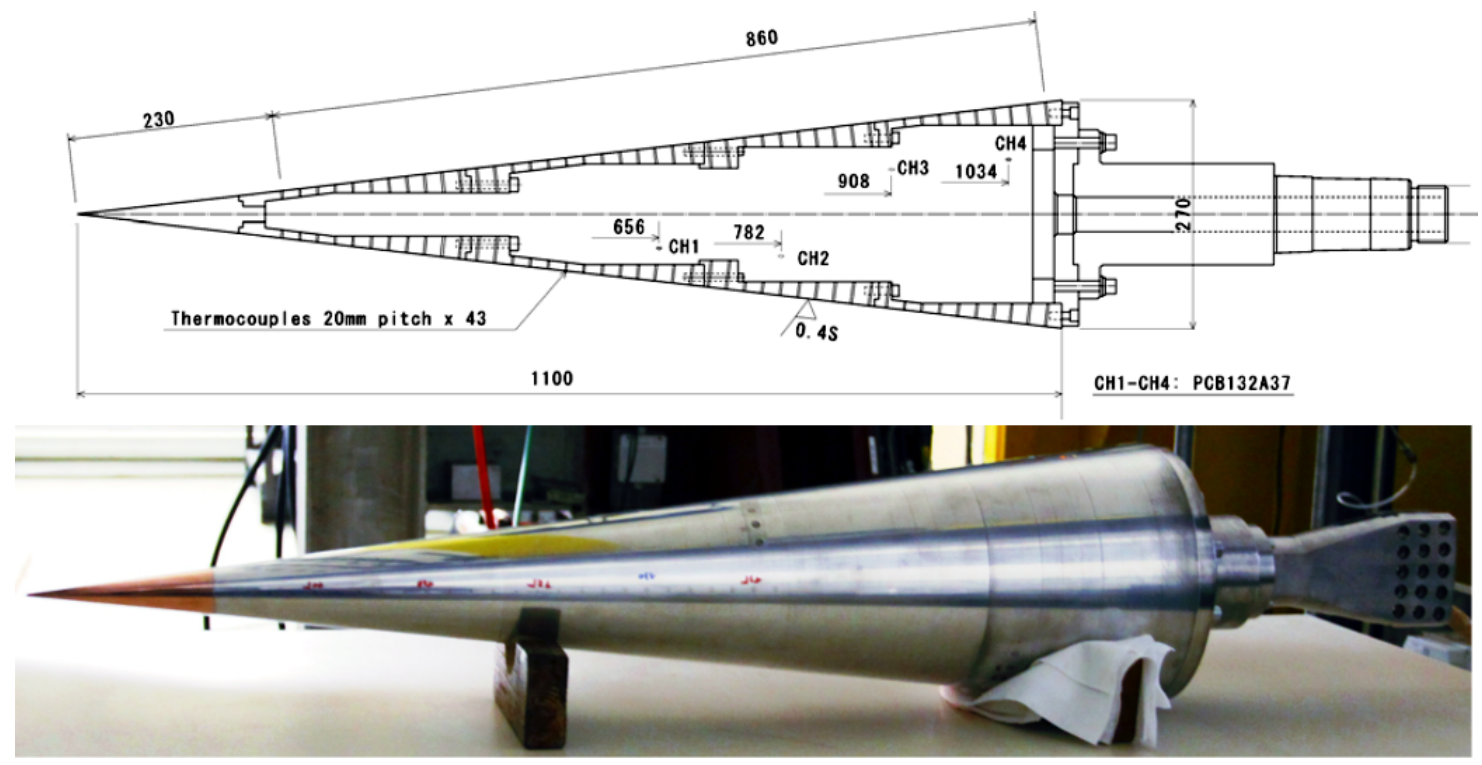

Figure 2. Technical drawing of the $7^{\circ}$ half-angle cone (top) (from Tanno et al. ${ }^{7}$ ) and photographic view of the model before mounting (bottom)

The instrumentation was chosen such that the transition location on the cone would be detectable by evaluating the surface heat-flux distribution obtained from the thermocouple readings. The flush-mounted 
KULITE pressure transducers were used to quantitatively measure the surface pressure so that the angle of attack and the yaw angle could be controlled. Eight PCB132A37 fast response pressure transducers were grouped in pairs and flush mounted along the model at $x=655.9 \mathrm{~mm}, x=782 \mathrm{~mm}, x=908 \mathrm{~mm}$ and $x=1034.1 \mathrm{~mm}$. These pressure transducers feature a resonance frequency of $1 \mathrm{MHz}$ or higher and were used to measure pressure fluctuations in the boundary-layer above the cone surface. Piezoelectric type pressure transducers are sensitive to accelerations present in the model during test time; for this reason, the pressure transducers were installed using cotton threads and silicone caulk to mechanically decouple the transducers and to reduce the transfer of high frequency vibrations from the model. ${ }^{7}$ Two additional blind reference pressure transducers of the same type were mounted at $x=908 \mathrm{~mm}$ and $x=1034.1 \mathrm{~mm}$ without access to the flow field using standard o-rings. These transducers were used to measure the frequency content of the mechanical vibrations that affected the transducer, despite the elaborate mounting. The recorded spectra were then used to correct the data of the transducers exposed to the flow field.

\section{Numerical Methods}

The laminar basic-flow calculations were performed with the DLR FLOWer code. ${ }^{9}$ The FLOWer code solves the compressible Reynolds-averaged Navier Stokes equations, which are written in the conservation law form, for a flow of a perfect gas on block-structured grids using second order finite volume techniques and cell-centered or cell vertex variables.

For the instability analyses the NOLOT code $^{4}$ was used, which was developed in cooperation between DLR and FOI and can be used for local as well as non-local analyses. In this work the local linear approach was used which is a subset of the nonlocal stability equations. The equations were derived from the equations of conservation of mass, momentum and energy, which govern the flow of a viscous, compressible, calorically ideal gas, formulated in primitive variables. All flow and material quantities are decomposed into the steady laminar basic flow $\bar{q}$ and the unsteady disturbance flow $\tilde{q}$.

$$
q\left(x^{1}, x^{2}, x^{3}, t\right)=\bar{q}\left(x^{1}, x^{2}\right)+\tilde{q}\left(x^{1}, x^{2}, x^{3}, t\right)
$$

The disturbance $\tilde{q}$ is represented as a harmonic wave

$$
\tilde{q}\left(x^{1}, x^{2}, x^{3}, t\right)=\hat{q}\left(x^{2}\right) \exp \left[i\left(\alpha x^{1}+\beta x^{3}-\omega t\right)\right]
$$

with the complex-valued amplitude function $\hat{q}$. Since NOLOT is a spatial code the wavenumbers $\alpha$ and $\beta$ are complex quantities and the frequency $\omega$ is a real value. The complex growth rate $\sigma$ is defined as $\sigma=-\alpha_{i}$. For the calculation of the $\mathrm{N}$-factors of the $e^{N}$-method the most amplified wave angle was used and the frequency was kept constant

$$
N=\ln \frac{a}{a_{0}}=\int_{x_{0}^{1}}^{x^{1}} \sigma d x^{1} .
$$

Here $x_{0}^{1}$ denotes the streamwise position where the disturbances starts to grow and $a_{0}$ is the amplitude at this position.

\section{Results}

Table 2 provides an overview of the nozzle reservoir conditions and the free-stream conditions with their variations for the present series of tests. The free-stream conditions were evaluated at the tip of the cone using the DLR TAU code. ${ }^{10}$ In order to increase or lower the unit Reynolds number, the nozzle reservoir pressure was changed accordingly. The stagnation enthalpy was held constant at approximately $3.4 \mathrm{MJ} / \mathrm{kg}$ to separate the impact of the unit Reynolds number on the transition location.

Figure 3 shows pressure traces of the nozzle reservoir pressure for each of the above tabulated conditions. The test time was chosen as indicated between 2 and $5 \mathrm{~ms}$, during which the stagnation pressure is approximately constant.

Figure 4 provides normalized heat-flux distributions along the cone x-axis for unit Reynolds numbers between $1.5 \times 10^{6} / \mathrm{m}$ and $6.8 \times 10^{6} / \mathrm{m}$ and for two different nose radii, $R_{N}=2.25 \mathrm{~mm}$ and $R_{N}=5 \mathrm{~mm}$. 


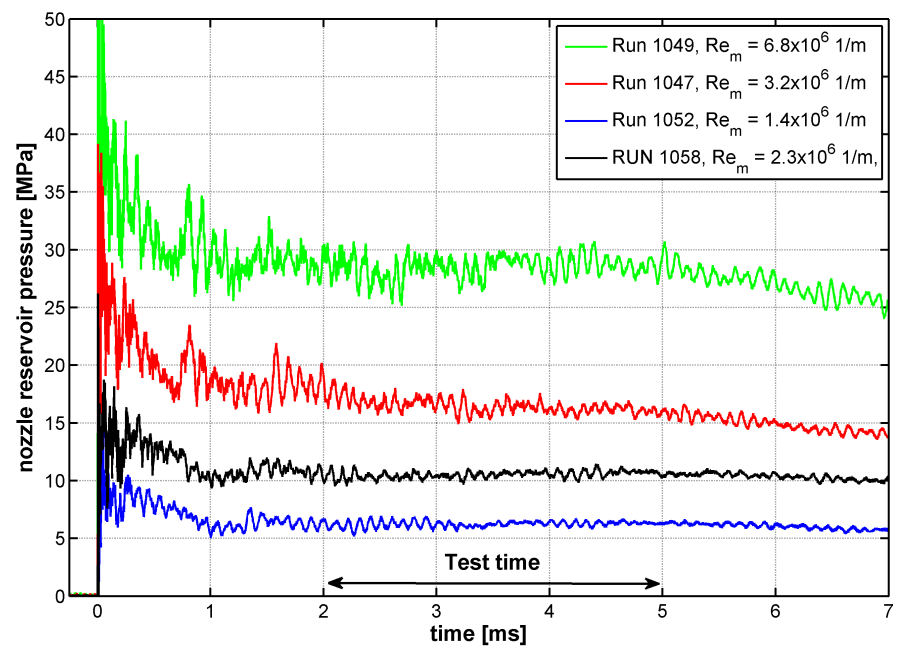

Figure 3. Nozzle reservoir pressure for runs 1047, 1049 and 1052 for enthalpy of $3 \mathrm{MJ} / \mathrm{kg}$, indicating the test time window

To provide a clear overview, the heat-flux distribution in each case was normalized by the heat-flux derived from the thermocouple at $x=230 \mathrm{~mm}$. The given unit Reynolds number, $R e_{m}$, was based on the free-stream conditions at the tip of the cone.

For a nose radius of $R_{N}=2.25 \mathrm{~mm}$ and a Reynolds number of $1.5 \times 10^{6} / \mathrm{m}$, the boundary-layer remains fully laminar on the complete model. An increase in unit Reynolds number results in laminar to turbulent transition at approximately $600 \mathrm{~mm}$ for $R e_{m}=3.2 \times 10^{6} / \mathrm{m}$. This corresponds to a transition Reynolds numbers of $R e_{t}=2.0 \times 10^{6}$. A further increase of the unit Reynolds number to $R e_{m}=6.8 \times 10^{6} / \mathrm{m}$ leads to transition at approximately $500 \mathrm{~mm}$, i.e. $R e=3.3 \times 10^{6}$.

Increasing the nose radius to $R_{N}=5 \mathrm{~mm}$ has a stabilizing effect on the transition process. Due to a lower growth rate of the instabilities, significantly higher transition Reynolds numbers can be observed. ${ }^{11}$ In the present tests, unit Reynold numbers of $R e_{m}=6.8 \times 10^{6} / \mathrm{m}$ resulted in transitions Reynolds numbers of $R e_{t}=5.3 \times 10^{6}$.

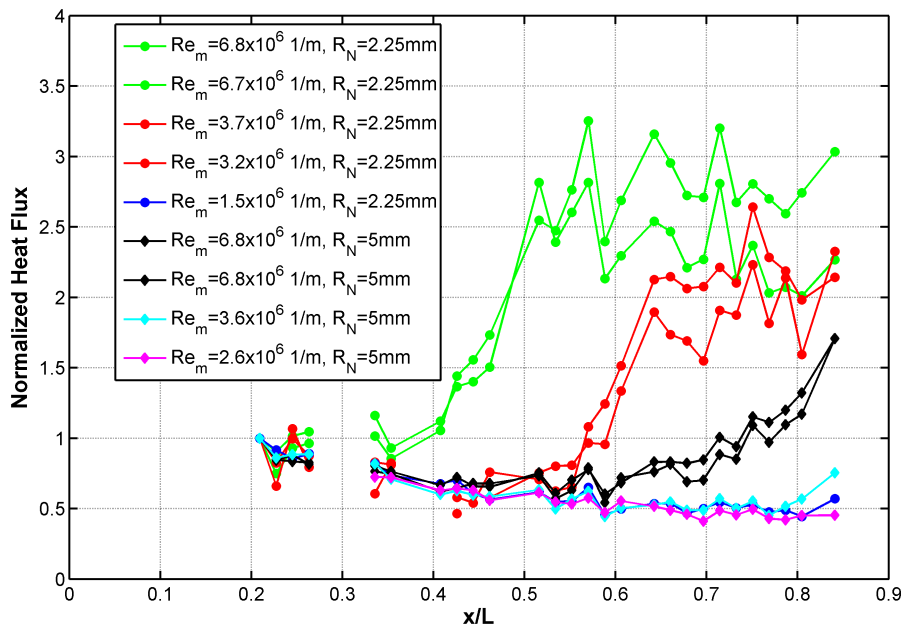

Figure 4. heat-flux distribution along the cone surface for unit Reynolds numbers between $R e_{m}=1.5 \times 10^{6} / m$ and $R e_{m}=6.8 \times 10^{6} / \mathrm{m}$ and nose radii of $R_{N}=2.25 \mathrm{~mm}$ and $R_{N}=5 \mathrm{~mm}$

Several runs were conducted with the same test conditions to confirm the repeatability of the tests. The run-to-run repeatability was found to be sufficiently good to see only minor changes of the transition position 
for the same test condition. A broader overview on the conducted tests and the obtained transition Reynolds numbers is provided in table 1.

By means of stability calculations using the NOLOT code, the expected distribution of the second mode instabilities along the cone surface was determined. To examine the boundary-layer for the presence of second mode instabilities, i.e. Mack modes, run 1058 was chosen. This test was conducted with a nose radius of $R_{N}=5 \mathrm{~mm}$ and a unit Reynolds number of $R e_{m}=2.3 \times 10^{6} / \mathrm{m}$; the thermocouple readings indicated that the heat-flux along the cone surface remained at laminar levels up to $x=990 \mathrm{~mm}$. The boundary-layer appeared to become transitional further downstream. The stability calculations of NOLOT, i.e. a linear, local stability analysis, predicted most amplified frequencies in a range between 200 and $350 \mathrm{kHz}$. That frequency range is well below the resonance frequency of the employed PCB pressure transducers and thus is expected to be resolvable.

In figure 5 the frequency spectra of the paired PCB pressure transducers at four different $\mathrm{x}$-coordinates along the cone are presented. The measured frequency spectra were corrected using the readings of the blind reference transducers. Since at the first two transducer locations $(x=655.9 \mathrm{~mm}, x=782 \mathrm{~mm})$ no reference transducers were available, these spectra were corrected using the readings obtained at $x=908 \mathrm{~mm}$.
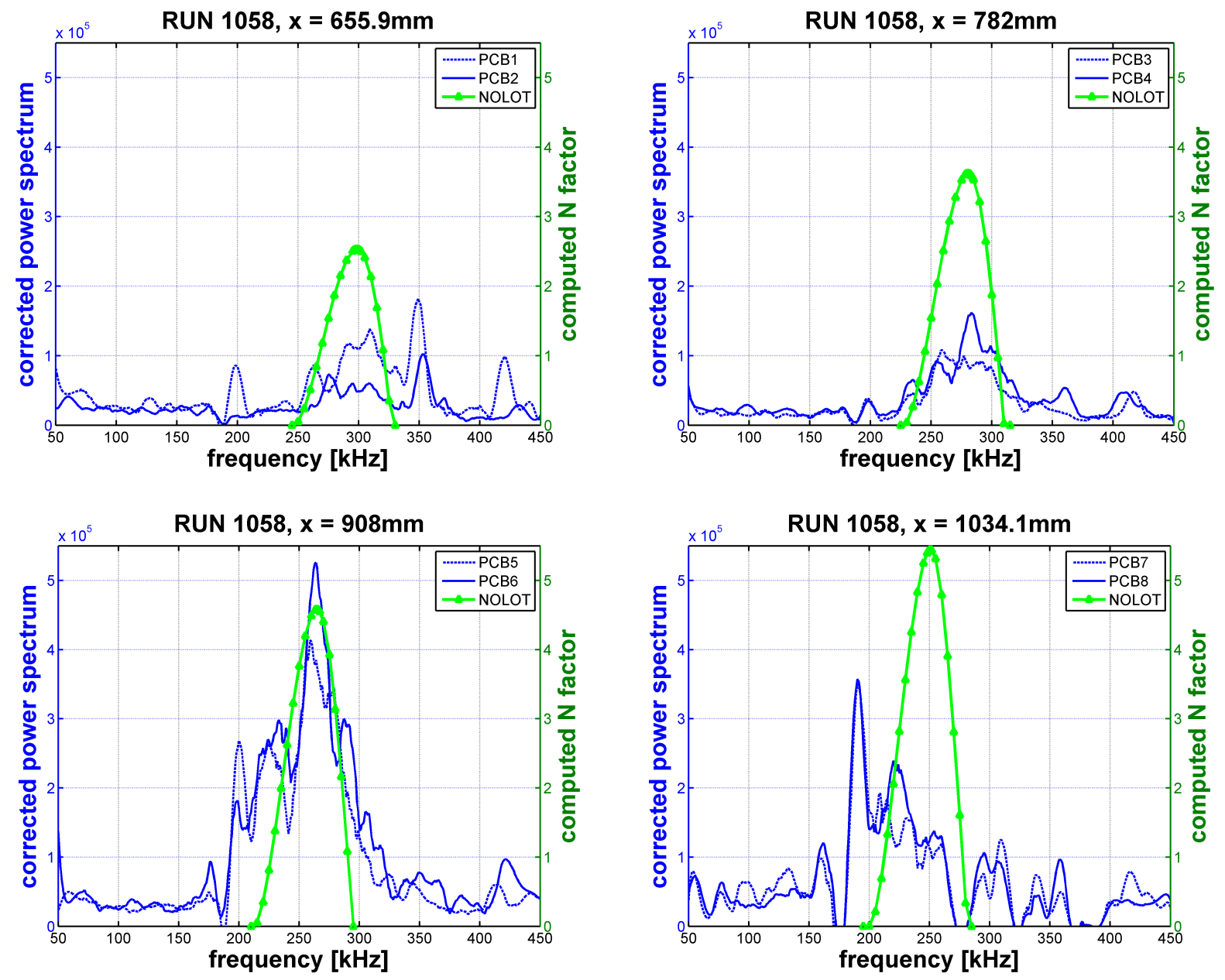

Figure 5. Computed $\mathrm{N}$ factors and corrected frequency spectra of the pressure fluctuations measured on the cone surface at four different positions: $x=655.9 \mathrm{~mm}, x=782 \mathrm{~mm}, x=908 \mathrm{~mm}$ and $x=1034.1 \mathrm{~mm}$

The correction function employed is indicated in figure 6 . The dashed blue line represents the frequency spectrum of a reference transducer. Since the reference transducers are not exposed to the flow it is assumed that their frequency content corresponds to mechanical vibrations of the model. To correct the transducers 
exposed to the flow for mechanical vibrations a correction function, indicated in green, was derived. The function was obtained by setting all values above a chosen amplitude to zero. Values below this amplitude were set to one. Subsequently, the spectra to be corrected were multiplied with the correction function. Thus, the obtained signals contain only those frequencies not identified as mechanical vibrations. To apply the correction function it was assumed that the mechanical properties of the o-ring mounted references transducers, used by DLR, are comparable to those of the cotton thread / silicone caulk mounted transducers used by JAXA. Furthermore, it is assumed that the mechanical vibrations are comparable along the model. This latter assumption allows the frequency spectra of the first two transducer locations to be corrected with reference measurements further downstream.

The corrected frequency spectra at each of the four positions on the model are shown in figure 5 , with the computed $\mathrm{N}$-factors at the four transducer positions on the cone overlaid. The frequency of the second mode instabilities is expected to decrease with the streamwise growing viscous boundary-layer while the amplitude of the pressure fluctuations increases. ${ }^{12}$ Furthermore, due to the breakdown of the instability waves a broadening of the spectra in the streamwise direction is expected. ${ }^{13}$ Comparing the predicted and measured most amplified frequencies in figure 5, good agreement at the positions $x=782 \mathrm{~mm}$ and $x=908 \mathrm{~mm}$ is observed. For the upstream position, i.e. $655.9 \mathrm{~mm}$, the most amplified frequency seems to be slightly underpredicted. In contrast, the frequency at $x=1034.1 \mathrm{~mm}$ seems to be slightly overpredicted. However, the expected streamwise decrease of the most amplified frequencies can be observed. Moreover, an increase of the fluctuation amplitude and a broadening of the spectrum towards $x=908 \mathrm{~mm}$ can be seen. The relatively weak signal at the last transducer position, $x=1034.1 \mathrm{~mm}$ may indicate breakdown into a transitional boundary-layer.

The conducted stability calculations provide a N-factor envelope such as that shown in figure 7 for run1049. The $\mathrm{N}$-factor distribution together with the measured transition location on the cone allows the determination of the $\mathrm{N}$-factor of the transition process. Table 1, provides an overview of a selection of tests, listing unit Reynolds number, transition Reynolds number and corresponding N-factor.

\begin{tabular}{c|c|c|c|c} 
& Run & $R e_{m}\left[\cdot 10^{6} / m\right]$ & $R e_{t}\left[\cdot 10^{6}\right]$ & N-factor \\
\hline$R_{N}=2.25 m m$ & 1052 & 1.4 & laminar & - \\
& 1053 & 1.5 & laminar & - \\
& 1054 & 1.4 & laminar & - \\
& 1046 & 3.7 & 2.1 & 5.7 \\
& 1047 & 3.2 & 2.0 & 5.6 \\
& 1055 & 3.7 & 2.3 & 6.0 \\
& 1049 & 6.8 & 3.3 & 7.1 \\
& 1050 & 6.4 & 3.1 & 6.6 \\
& 1051 & 6.7 & 3.2 & 6.7 \\
\hline$R_{N}=5 m m$ & 1058 & 2.3 & laminar & - \\
& 1061 & 2.6 & laminar & - \\
& 1059 & 3.6 & 3.1 & 5.6 \\
& 1060 & 6.8 & 5.2 & 6.0 \\
& 1065 & 6.8 & 5.3 & 6.5
\end{tabular}

Table 1. Transition Reynolds numbers and N-factors

The determination of the N-factors is very sensitive to the transition location and the free-stream conditions. The transition location was chosen as the first transducer position showing a rise in heat-flux towards the turbulent level. The uncertainty in this approach is higher for gradual transition. This is particularly the case for a nose radius of $R_{N}=5 \mathrm{~mm}$. The free-stream conditions were obtained by nozzle calculations using the DLR TAU code. All stability calculations are based on the nozzle exit conditions. 


\section{Conclusion}

Hypersonic boundary-layer transition was investigated on a $7^{\circ}$ half-angle cone with nose radii of $R_{N}=2.25 \mathrm{~mm}$ and $R_{N}=5 \mathrm{~mm}$ in the High Enthalpy Shock Tunnel Göttingen (HEG).

In the scope of the study, heat-flux and pressure measurements were obtained from thermocouples and flushmounted piezoelectric pressure transducers, respectively. Furthermore, stability calculations using the DLR code NOLOT were performed.

Depending on the test condition, transition Reynolds numbers between $R e_{t}=2.0 \times 10^{6}$ and $R e_{t}=5.3 \times 10^{6}$ were obtained. The corresponding N-factors vary between 5.6 and 7.1. The repeatability of the measurements was shown to be typical of reflected shock wind tunnels. To improve the evaluation of the data obtained with mechanically sensitive pressure transducers, a correction function was derived using reference transducers not exposed to the flow. Using this technique second mode instabilities were measured on the model surface. Good agreement was obtained between the experimental data and the stability calculation by NOLOT.

\section{Appendix}

\begin{tabular}{l|c|c|c|c} 
Operating Condition & XIII & XIV & XV & XVII \\
\hline$p_{0}[M P a]$ & $15.8 \pm 2.4 \%$ & $6.3 \pm 2.2 \%$ & $28.0 \pm 2.8 \%$ & $10.6 \pm 2.8 \%$ \\
$T_{0}[K]$ & $2620 \pm 1.1 \%$ & $2640 \pm 0.5 \%$ & $2610 \pm 1.3 \%$ & $2620 \pm 2.0 \%$ \\
$H_{0}[M J / k g]$ & $3.37 \pm 1.3 \%$ & $3.34 \pm 0.3 \%$ & $3.36 \pm 1.5 \%$ & $3.37 \pm 2.0 \%$ \\
$T_{\infty}[K]$ & $275 \pm 5.2 \%$ & $270 \pm 0.5 \%$ & $265 \pm 1.5 \%$ & $270 \pm 3.3 \%$ \\
$\rho_{\infty}\left[\mathrm{g} / \mathrm{m}^{3}\right]$ & $25 \pm 5.7 \%$ & $10 \pm 0.5 \%$ & $47 \pm 3.6 \%$ & $18 \pm 1.7 \%$ \\
$u_{\infty}[\mathrm{m} / \mathrm{s}]$ & $2390 \pm 1.9 \%$ & $2370 \pm 0.3 \%$ & $2360 \pm 0.6 \%$ & $2370 \pm 1.0 \%$ \\
$\operatorname{Re}_{m}\left[10^{6} / \mathrm{m}\right]$ & $3.6 \pm 10 \%$ & $1.4 \pm 3 \%$ & $6.7 \pm 4 \%$ & $2.5 \pm 6 \%$
\end{tabular}

Table 2. Operating conditions of the presented study in HEG (enthalpy reference temperature at $T=0 K$ )

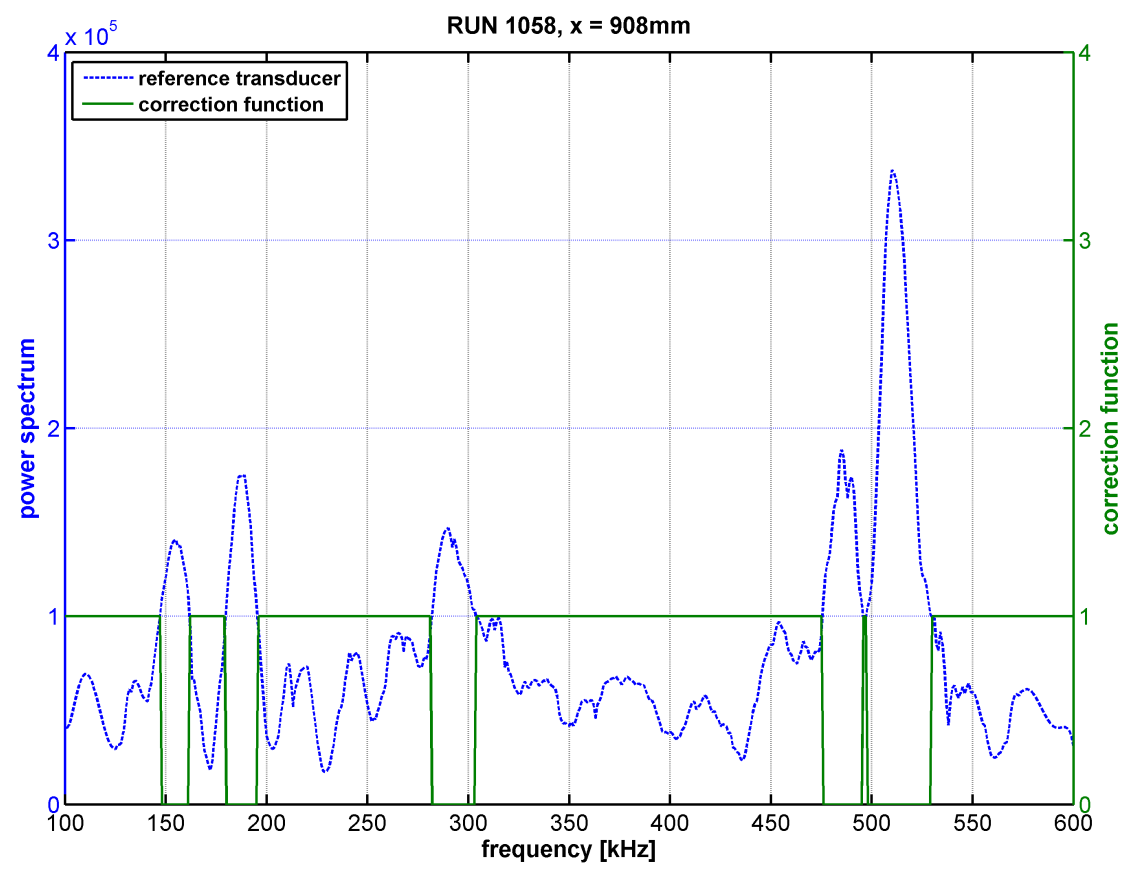

Figure 6. Spectrum of a PCB pressure transducer not exposed to the flow field and the derived correction function 


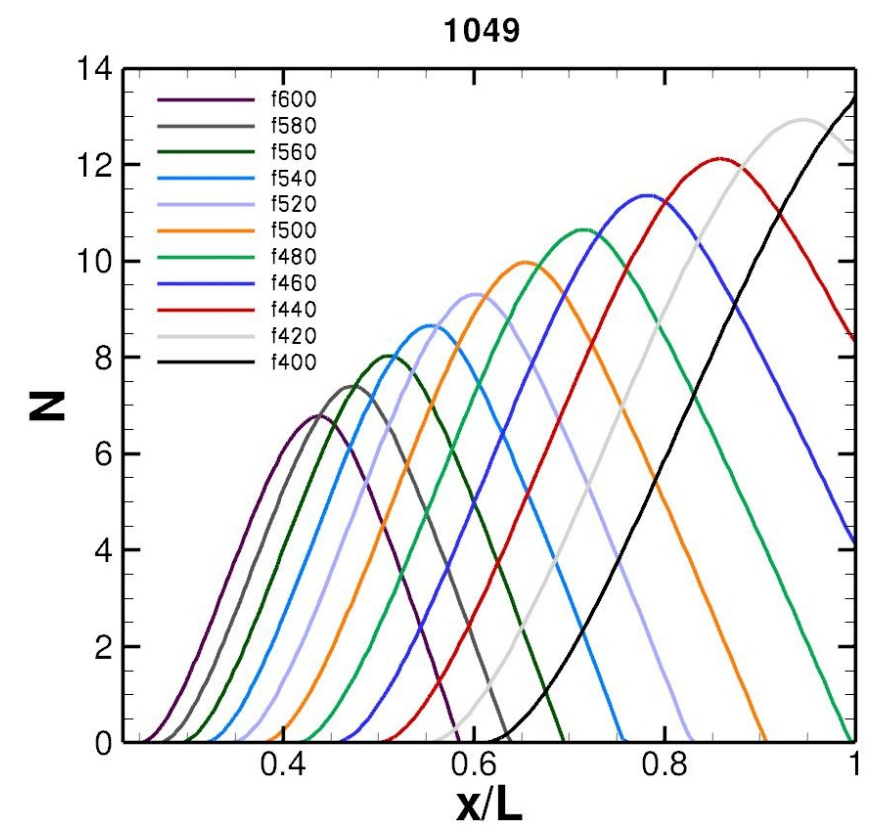

Figure 7. N-factor envelope for run 1049 (condition XV in table 2)

\section{Acknowledgments}

The presented work was conducted in the framework of the DLR internal project IMENS-3C and the DLR-JAXA Cooperative Task: High Enthalpy Aerothermodynamics .

\section{References}

1 Schneider, Steven P.: Flight data for boundary-layer transition at hypersonic and supersonic speeds. In: Journal of Spacecraft and Rockets 36 (1999), January-February, Nr. 1, S. 8-20

2 Pate, S. R. ; Schueler, C. J.: Radiated Aerodynamic Noise Effects on Boundary-Layer Transition in Supersonic and Hypersonic Wind Tunnels. In: AIAA Journal 7 (1969), S. 450-457

3 Itoh, K. ; Ueda, S. ; Tanno, H. ; Komuro, T. ; Sato, K.: Hypersonic Aerothermodynamic and Scramjet Research Using High Enthalpy Shock Tunnel. In: Shock Waves 12 (2002), S. 93-98

4 Hein, S. ; Bertolotti, F. P. ; Simen, M. ; Hanifi, A. ; Henningson, D.: Linear nonlocal instability analysis - the linear NOLOT code / DLR. 1994 (IB-223-94 A56). - Forschungsbericht

5 Hannemann, K. ; Martinez Schramm, J. ; Karl, S.: Recent extensions to the High Enthalpy Shock Tunnel Göttingen (HEG). In: Proceedings of the 2nd International ARA Days Ten Years after ARD,. Arcachon, France, October 2008

6 Hannemann, K. ; Martinez Schramm, J. ; Tropea, C. (Hrsg.) ; Foss, J. (Hrsg.) ; Yarin, A. (Hrsg.): High Enthalpy, High Pressure Short Duration Testing of Hypersonic Flows, In: Springer Handbook of Experimental Fluid Mechanics. Springen Berlin Heidelberg, 2007

7 Tanno, Hideyuki ; Komuro, Tomoyuki ; Sato, Kazuo ; Iтон, Katsuhiro ; TAKahashi, Masahiro ; FujıI, Keisuke: Measurement of hypersonic boundary layer transition on cone models in the free-piston shock tunnel HIEST. In: $47 t h$ AIAA Aerospace Sciences Meeting. Orlando, Florida: AIAA, January 2009. - AIAA 2009-781

8 Wadhams, T.P. ; Mundy, E. ; Lean, M. G M. ; Holden, M. S.: Ground Test Studies of the HIFiRE-1 Transition Experiment Part 1: Experimental Results. In: Journal of Spacecraft and Rockets 45 (2008), November-December, Nr. 6, S. 1134-1148. - study for flight test

9 Kroll, N. ; Fassbender, J. K.: MEGAFLOW - Numerical Flow Simulation for Aircraft Design. Springer Berlin, 2005

${ }^{10}$ Reimann, Bodo ; Hannemann, Volker: Numerical Investigation of Double-Cone and Cylinder Experiments in High Enthalpy Flows using the DLR TAU code. In: 48th AIAA Aerospace Sciences Meeting Including the New Horizons Forum and Aerospace Exposition. Orlando, USA, January 2010

${ }^{11}$ Rosenboom, I. ; Hein, S. ; Dallmann, U.: Influence of Nose Bluntness on Boundary-Layer Instabilities in Hypersonic Cone Flows. In: 3Oth AIAA Fluid Dynamics Conference, 1999

${ }^{12}$ Stetson, K. F. ; Kimmel, Roger L.: On Hypersonic Boundary-Layer Stability. In: 30th Aerospace Sciences Meeting 83 Exhibit. Reno, NV : AIAA, January 1992. - AIAA-92-0737

${ }^{13}$ Estorf, Malte ; Radespiel, Rolf ; Schneider, Steven P. ; Johnson, Heath B. ; Hein, Stefan: Surface-Pressure Measurements of Second-Mode Instability in Quiet Hypersonic Flow. In: 46th AIAA Aerospace Sciences Meeting and Exhibit. Reno, Nevada, January 2008. - AIAA 2008-1153 